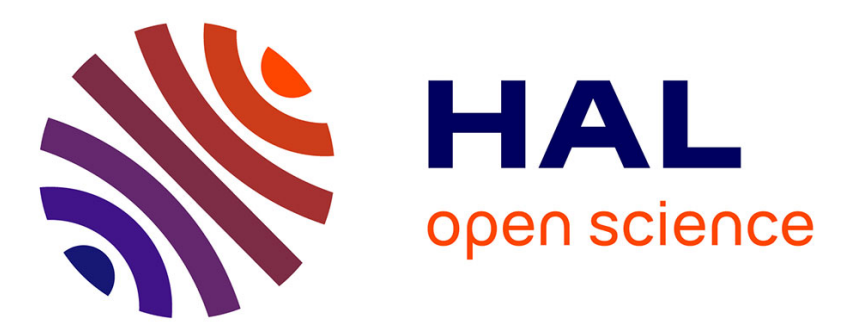

\title{
Big Data Analytics for Logistics and Distributions Using Blockchain
}

Benedito Cristiano A. Petroni, Elisângela Moraes, Rodrigo Franco Gonçalves

\section{To cite this version:}

Benedito Cristiano A. Petroni, Elisângela Moraes, Rodrigo Franco Gonçalves. Big Data Analytics for Logistics and Distributions Using Blockchain. IFIP International Conference on Advances in Production Management Systems (APMS), Aug 2018, Seoul, South Korea. pp.363-369, 10.1007/9783-319-99707-0_45 . hal-02177882

\section{HAL Id: hal-02177882 \\ https://hal.inria.fr/hal-02177882}

Submitted on 9 Jul 2019

HAL is a multi-disciplinary open access archive for the deposit and dissemination of scientific research documents, whether they are published or not. The documents may come from teaching and research institutions in France or abroad, or from public or private research centers.
L'archive ouverte pluridisciplinaire HAL, est destinée au dépôt et à la diffusion de documents scientifiques de niveau recherche, publiés ou non, émanant des établissements d'enseignement et de recherche français ou étrangers, des laboratoires publics ou privés. 


\title{
Big data analytics for logistics and distributions using Blockchain
}

\author{
Benedito Cristiano A. Petroni ${ }^{10000-0001-9826-1257]}$, Elisângela Mônaco de Moraes ${ }^{20000-}$ \\ 0002-0461-5235], Rodrigo Franco Gonçalves 3[0000-0003-2206-3136] \\ ${ }^{1}$ Universidade Paulista, Jundiaí, Brasil \\ ${ }^{2,3}$ Universidade Paulista, São Paulo, Brasil \\ benedito.petroni@docente.unip.br \\ elisangela.moraes@docente.unip.br \\ rofranco212@gmail.com
}

\begin{abstract}
The volume of data generated is increasing. Companies capture large amounts of bytes of information about customers, vendors, products, sensory components, and especially their manufacturing operations. However, important problems, such as the Supply Chain Management processes, present difficulties regarding the security, integrity and validity of information generated in different databases. Blockchain technology presents itself as a disruptive process control technology where, through Smart Contracts, it provides transaction reliability and assures the parties involved that its purpose is strictly adhered to. Meanwhile, Big Data is offered as a solution to analyze all the information originated from the operations generated. In this article, as a contribution, possibilities of information generation will be presented, with the interaction of Blockchain, Cyber Physical Systems, Internet of Things technologies in function of the Supply Chain Management processes, so that they can later be analyzed through Big Data, giving users better controls and decision management in favor of improving their business.
\end{abstract}

Keywords: Blockchain, Big Data Analytics, Cyber Physical Systems.

\section{$1 \quad$ Introduction}

Industry 4.0 has led to several discussions concerning industrial processes, services and controls, and is considered a new potential to affect industries in their business, projects, manufacturing and deliveries [2]. Logistic management, a major part of an SCM system, has over the years ceased to be a simple activity of conferring and transporting products between companies, becoming a complex structure of collaborative analysis among all departments involved in its process. Despite logistical management, numerous devices and sources generate every second a large amount of unstructured data in the most diverse databases for its operations, and in addition, the amount of data created each year is much larger than the one created previously [1], thus requiring an attention 
to an effective analysis of its contents, mainly regarding security, integrity and reliability of the information. New technologies have promoted research that seeks to transform SCM processes and bring about changes in the way we produce, market, buy, consume and mainly how we control our goods and products, [4], allowing analyzes of the necessary information that can corroborate in future decisions. There is currently a growing interest in companies to gain insight into the origins of consumer products and the demand for sustainable transportation, where products are imported and sold with the limited information of a label addressing the origins of manufacturing or production [ 5]. It was traumatic for many managers not to have real-time information on product supply in the gondola or delivered to an end consumer through channels specifically set up for such purpose as e-commerce. [23]. The SCM processes represent all the links involved in the creation and distribution of goods, from raw materials to the finished product that will be in the consumer's possession. Supply chains can presently span hundreds of stages and dozens of geographic locations, making it very difficult to trace events or investigate incidents [6], thereby ensuring the safety and integrity of the entire process. Modern vehicles in intelligent transport systems can communicate with each other, as well as roadside infrastructure units, in order to increase transport efficiency and road safety. For example, there are techniques to alert drivers in advance about traffic incidents and to help them avoid congestion, [7]. On the other hand, threats to such systems may limit the benefits of such technologies, as they rely on technological environment boundaries, poorly connected and mainly centralized information. In this article, issues such as the decentralization of information regarding SCM, security and integrity will be provoked by the proposal of integration of technologies such as blockchain, Internet of Things - IoT, Cyber Physical Systems - CPS and Big Data in its favor.

\section{The Literature}

\subsection{Industry 4.0.}

The evolutionary process of the German initiative, the Industry 4.0 is bringing to organizations new perspectives and improvements in services and production methods.

After two or three years of discussions on Industry 4.0, many companies currently have smart factory active designs projects [10]. The Industry 4.0 focused on the establishment of manufacturing components and intelligent objects as well as new production processes [11]. Technologies that capture the exclusive needs of factory floor users will decide the future of this new world, and yet with the possibility of deeply analyzing all user information.

\section{Internet of Things - IoT}

In organizations, the Internet is allowing a huge leap in productivity because the emerging IoT is the first intelligent infrastructure revolution in history, wich will connect every device, company, residence, vehicle in an intelligent network in an Internet as a 
network communications, energy, transport, and all of them are embedded in a single operating system [12].

Although recent developments have made IoT a reality, there are a number of challenges to be addressed in order to realize its full potential and to bring tangible benefits to society, the environment, the economy and individual citizens. [13] Divices will be able to make intelligent decisions, so that many workflows will be automated in new ways, resulting in significant time and cost savings [23]. However, true revolution can happen if all devices are controlled for example by a platform, in the blockchain case, where instead of direct user control it can be using Smart Contracts, with the conditions and rules of the business that must be dealt with before a transaction is included in the blockchain [23]. Therefore, IoT and Industry 4.0 are being increasingly interlinked in order to create more opportunities by providing new types of services and business models of value chain interaction [17].

\section{Cyber Physical Systems}

The multiple and distinct behavioral modalities with the interaction of one with the other object in a multitude of ways that change according to the application context [21], are part of the context of the CPS. Its operation involves different fields, such as network of distributed sensors, intelligent network [16], medical monitoring, process control system among others, being the communication capacity between virtual objects and processes with real object and production processes one of the most important of this technology [15]. In CPS all computing and communication layers are incorporated in all types of objects and structures in the physical environment [18]. According to [19], the CPS consider in their implementation a combination of embedded hardware and software technologies, and in its interaction with the physical world it is considered the use of large monitoring structures composed of networks of sensors and actuators for the execution of the tasks.

\subsection{Blockchain}

Blockchain technology fits into a relatively new research area in different forms and possibilities for applications in a new generation of transactional applications. Its popularization is directly linked as being the basis of the model of the Bitcoin criptosmoeda created by Satoshi Nakamoto, where in a file somewhere represents the transactions carried out and registered.

Each blockchain, such as that used by the Bitcoin cryptomoeda is distributed, running on volunteer computers around the world, so there is no central database, [3]. In essence, the blockchain is a public book that contains information about each transaction made within a system known as peer to peer, or point to point [5].

Blockchain is an incorruptible ledger that stores all data exchanges that occur on the network, built over time and maintained by the collaboration of all of us in a particular network - the user can be sure that the data is accurate [3].

This technology is being viewed as a revolutionary solution, addressing modern technology concerns such as decentralization, trust, identity, data ownership, and datadriven decisions. While actively looking for the best way to store, organize and process 
Big Data, block-chain technology provides a significant contribution, [27]. A certain process, being manufacturing or logistic, will have its registration in a block of records and from this, all its contents will become immutable, that is, no more changes are allowed, thus guaranteeing security and integrity in the process.

In this process, all network members can check all their transactions in the block chain, if no consensus on the validity of the new block is reached, the block will be rejected [6]. Similarly, if there is a consensus that the transactions in the block are valid, the block is added to the chain, thereby forming a specific blockchain that can be applied to SCM and logistics processes.

The guarantee of this process is in the generation of a cryptographic file -hash (file that ensures the integrity of the information) that is generated for each block, which contains not only transaction logs, but also the hash of the previous block, creating a block interdependence linking to a chain thus forming the blockchain.

\subsection{Big Data Analytics}

Big Data is the term that describes a huge, structured, and generally unstructured set of data that requires real-time analysis, independent of the storage medium. An important aspect in this respect is the efficient management of business processes and risks [8].

Some concepts are common in terms of definitions found as: Reference to large volumes of data ( $>1$ bytes Peta), different types of structured and unstructured data, faster generation of data through different sources and new ways of storing, process, analyze, visualize and integrate the data.

There are a variety of definitions found on Big Data and similarly it repeats with respect to Big Data techniques and technologies. There are some Big Data aspects [22]: Big Data Analysis techniques, Big Data techniques and visualization. Organizations in many industrial sectors can take advantage of these important data to facilitate the discovery of new ideas, with the effective use of large data, has the potential to transform economies, providing a new wave of productivity growth involving SCM, as well as the controls of distribution and delivery to the end user.

\section{$3 \quad$ Blockchain applied in SCM and logistics processes}

As a critical issue, one of the elements of the SCM, logistics is treated taking into account some security risks and with a direct tendency to centralize its operations, because even with supporting technologies - IoT, CPS and cloud computing, these can temporarily be unavailable due to attacks, performance limitations and even improper operations, [9].

With this, blockchain technology presents itself as a great potential to improve processes and security models in the SCM area, especially in logistics. However, according to some recent studies on trends in SCM and logistics, the blockchain is known only by some experts and still in a small number by those who search for implementation plans 
[20]. This technology enables intelligent devices with relevant information from manufacturing processes to be programmed for actions in defined circumstances without risk of error and tampering, by implementing Smart Contracts. With this, it is possible to record all transactions that occurred with Smart Contracts in its ledger of all SCM processes. Still, according to the inherent characteristics of blockchain technology, such as the execution of Smart Contracts, it is not only possible to apply it to productive processes, but also to consider how these technologies are applied in practically the entire production chain, as can be observed in Fig. 1 below:

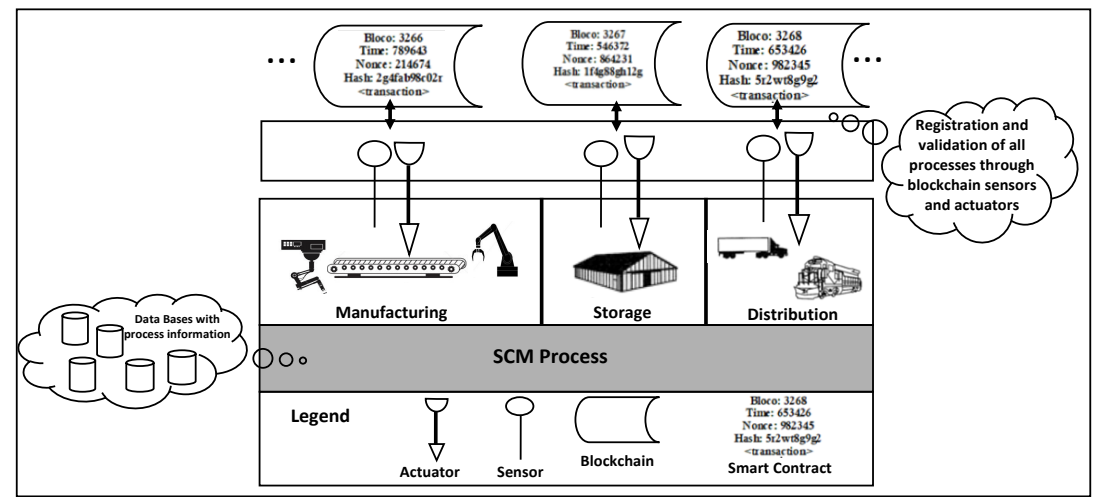

Fig. 1. Blockchain applied to SCM processes

As explained in Fig. 1, all SCM processes such as manufacturing, storage and distribution are executed according to certain rules derived from the Smart Contracts executed on the blockchain platform, on all the validation processes by the network members and the interaction with IoT and CPS components.

Thus, blockchain aggregates all computing resources in the resolution of previously intractable problems, for example, more refined real-time transport management and control [9], with the integrity and security of the information until the final consumer with its records . In this way, it is possible to efficiently guarantee the security, integrity and authenticity of the entire block chain.

Once all the information has been stored, they can be analyzed in detail through Big Data. In Fig. 2 below, all the information from the validated and secure SCM processes by the blockchain platform as well as all the processes that have been stored in several databases, using Big Data technology, analysis of information can be carried out in order to obtain knowledge stored in the aid in the decision-making process.

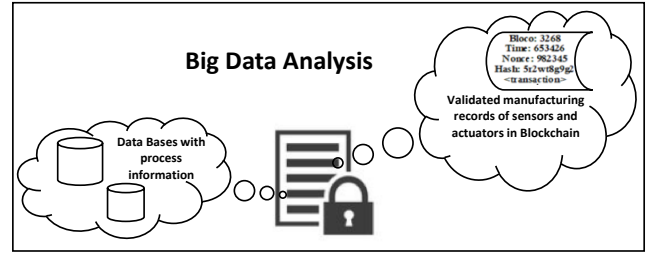

Fig. 2. Analysis of information by Big Data. 
Thus, through Big Data, all the information contained in the databases can be processed and analyzed, but remains private or semi-private [22], and through mass collaboration and cryptographic mechanisms all information has become secure, in this way, all the records of the blocks contained in the blockchain platform will be analyzed.

\section{Conclusion}

With the article information, it has been shown that, with the advent experienced by IoT and elements of the CPS everything can be registered, informed and stored. Blockchain technology through Smart Contracts and encrypted storage can authenticate all stages of the production and logistics chain, that is, from the manufacturing process, from the modes of transport to the final consumer, registering in the books with security, transparency and integrity.

Big Data technology will be able through its analytical techniques provide valueadded to companies with knowledge for improvements in manufacturing processes and future decision making. As blockchain technology is still considered embryonic, new studies are sure to emerge to further explore possibilities and needs with further detailed investigations of the applications.

\section{References}

1. AYED, A. Ben, M. Ben Halima, A. M. Alimi, Big data analytics for logistics and transportation, 2015 4th International Conference on Advanced Logistics and Transport (ICALT), Valenciennes, 2015, pp. 311-316.

2. HOFMANN, Erik, Marco Rüsch, Industry 4.0 and the current status as well as future prospects on logistics, In Computers in Industry, Volume 89, 2017, pp 23-34

3. TAPSCOTT, Don, Alex T., Blockchain: como a tecnologia por trás do Bitcoin está mudando o dinheiro, os negócios e o mundo. - São Paulo: SENAI-SP Editora, 2016.

4. DICKSON, B. (2016). Blockchain has the potential to revolutionize the supply chain. [online] Techcrunch. Available at: https://techcrunch.com/2016/11/24/ [Acesso em 12/11/2017].

5. SADOUSKAYA, K. (2017), Adoption of Blockchain Technology in Supply Chain and Logistics, Unpublished Bachelor's Thesis, Kymenlaakso University of Applied Sciences,Kotka, Finland.

6. MORITZ, Petersen, \& Hackius. Mapping the Sea of Opportunities: Blockchain in Supply Chain and Logistics. 2017.

7. L. Ming, G. Zhao, M. Huang, X. Kuang, H. Li and M. Zhang, "Security Analysis of Intelligent Transportation Systems Based on Simulation Data," 2018 1st International Conference on Data Intelligence and Security (ICDIS), South Padre Island, TX, USA, 2018, pp. 184-187

8. T. NIESEN, et al., Towards an Integrative Big Data Analysis Framework for Data-Driven Risk Management in Industry 4.0. System Sciences (HICSS), 49th Hawaii International Conference, 2016

9. Y. Yuan and F. Y. Wang, "Towards blockchain-based intelligent transportation systems," 2016 IEEE 19th International Conference on Intelligent Transportation Systems (ITSC), Rio de Janeiro, 2016, pp. 2663-2668.

10.ZEZULKA, F., P.Marcon, I.Vesely, O.Sajdl, Industry 4.0 - An introduction in then phenomenon. IFAC-Papers OnLine, V. 49, Issue 25, 2016, 8-12 pp.

11.RAJKUMAR R., I. Lee, L. Sha and J. Stankovic, Cyber-physical systems: The next computing revolution Design Automation Conference, Anaheim, CA, 2010, pp. 731-736. 
12.L. YANG, Industry 4.0: A Surveyon Technologies, Applications and Open Research Issues, Journal of Industrial Information Integration (2017).

13.SCHEUERMANN, C., S. Verclas and B. Bruegge, Agile Factory - An Example of an Industry 4.0 Manufacturing Process, IEEE 3rd International Conference on Cyber-Physical Systems, Networks, and Applications, Hong Kong, 2015, pp. 43-47.

14.D. Wang, "Building Value in a World of Technological Change: Data Analytics and Industry 4.0," in IEEE Engineering Management Review, vol. 46, no. 1, pp. 32-33, Firstquarter,march 12018.

15.KERSTEN, W., M. Seiter, B. von See, N. Hackius, and T. Maurer (2017). Trends and Strategies in Logistics and Supply Chain Management - Digital Transformation Opportunities. Hamburg: DVV Media Group.

16.JAMES Manyika et al., "Big data: The next frontier for innovation, competition, and productivity," McKinsey Global Institute, May 2011.

17.BERTAGLIA, Paulo, Desmistificando a Manufatura 4.0, Disponível em https://www.linkedin.com/pulse/desmistificando-manufatura-40-paulo-roberto-bertaglia/, last accessed 02/04/2018.

18.SCHEUERMANN, C., S. Verclas and B. Bruegge, "Agile Factory - An Example of an Industry 4.0 Manufacturing Process", IEEE 3rd International Conference on Cyber-Physical Systems, Networks, and Applications, Hong Kong, 2015, pp. 43-47.

19.GARAY, Jorge Rodolfo Beingolea. CyberSens: uma plataforma para redes de sensores em sistemas ciber-físicos. 2012. Tese (Doutorado em Sistemas Eletrônicos) - Escola Politécnica, Universidade de São Paulo, São Paulo, 2012.

20.KERSTEN, W., M. Seiter, B. von See, N. Hackius, and T. Maurer (2017). Trends and Strategies in Logistics and Supply Chain Management - Digital Transformation Opportunities. Hamburg: DVV Media Group.

21.KHAITAN et al., Design Techniques and Applications of Cyber Physical Systems: A Survey, IEEE Systems Journal, 2014

22.JAMES Manyika et al., "Big data: The next frontier for innovation, competition, and productivity," McKinsey Global Institute, May 2011

23..J. Herrera-Joancomartí and C. Pérez-Solà, "Privacy in Bitcoin Transactions: New Challenges from Blockchain Scalability Solutions," Modeling Decisions for Artificial Intelligence, pp. 26-44, 2016.

24.KARAFILOSKI E., A. Mishev, "Blockchain solutions for big data challenges: A literature review" IEEE EUROCON 2017 -17th International Conference on Smart Technologies, Ohrid, 2017, pp. 763-768. 